\title{
ANALISA PERUBAHAN GARIS PANTAI AKIBAT BANGUNAN PENGAMAN PANTAI (GROIN) DI PANTAI SALIDO PESISIR SELATAN SUMATERA BARAT
}

\author{
Wazer El Hamidi ${ }^{1}$ Junaidi $^{* 2}$, Ahmad Junaidi ${ }^{3}$, Abdul Hakam ${ }^{4}$ \\ ${ }^{1}$ Mahasiswa, Magister Teknik Sipil, Fakultas Teknik, Universitas Andalas \\ 2,3,4Dosen, Teknik Sipil, Fakultas Teknik, Universitas Andalas \\ Korespondensi: junaidi@eng.unand.ac.id
}

\begin{abstract}
In 2015, the government, through the Regional Office V Sumatra River, building groynes and jetties to maintain of the Salido coastline. But development is limited to the Salido coastline, while Salido position is the one with the coastline of Sago which is located in the northwest. So, the author is interested to research whether the construction of groynes have an impact on areas that are not built and whether the groynes effective to deal with the instability of the coastline, by simulating changes in the coastline in the next 10 years. The study results also show that the groynes is effective in maintaining the stability of the Salido coastline. While the impact of groynes in areas not built is abrasion on the downstream side of the last groyne bordering the Sago coastline \pm 78 meters, and the deterioration of the coastline \pm 18 meters by simulating 10 years into the future. After the construction of groynes, Sago beach will no longer accreting or abrasion (accretion occurs earlier). Abrasion on the downstream side of last groins are likely to increase so that development needs to be done along the Sago shoreline.
\end{abstract}

Keywords : Genesis, groyne, shoreline changes.

\section{PENDAHULUAN}

Perubahan garis pantai merupakan fenomena dinamika alami yang terjadi pada pantai di seluruh dunia. Secara sederhana proses perubahan garis pantai disebabkan oleh angin dan air yang bergerak dari suatu tempat, mengikis pasir dan sedimen kemudian memindahkan dan mengendapkannya ke tempat yang lain secara kontinu. Kondisi seperti ini sangat dipengaruhi oleh proses-proses yang terjadi pada daerah sekitar pantai (nearshore process), karena pada lokasi ini pantai selalu beradaptasi dengan berbagai kondisi yang terjadi [1]. Proses ini berlangsung dengan sangat kompleks dan dipengaruhi oleh tiga faktor utama yaitu kombinasi gelombang dan arus, transport sedimen dan konfigurasi pantai yang saling mempengaruhi satu sama lain.

Pantai Salido terletak $\pm 75 \mathrm{~km}$ sebelah selatan Kota Padang tepatnya di Kecamatan IV Jurai pada $100^{\circ} 32^{\prime}-100^{\circ} 47^{\prime}$ Bujur Timur dan $1^{\circ} 9,70^{\prime}-1^{\circ} 22,70^{\prime}$ Lintang Selatan. Pantai Salido merupakan lidah pasir (sandpit) yang membentang sepanjang $\pm 6 \mathrm{~km}$ karena terdapat aliran sungai batang Salido di belakang garis pantai Salido. Fluktuasi debit batang Salido menyebabkan muara sungai batang Salido berpindah-pindah sehingga menyebabkan bentuk garis pantai Salido menjadi tidak stabil. Pada tahun 2015 Kementerian PUPR melalui Balai Wilayah Sungai Sumatera V membangun bangunan pengaman pantai berupa groin dan jetty pada pantai Salido untuk menjaga kestabilan garis pantai Salido. Dalam pelaksanaannya pembangunan groin harus dibangun dalam satu seri yang terdiri dari beberapa groin, dengan panjang dan jarak antar groin sedemikian rupa sehingga kemungkinan erosi pada zona di luar downdrift akibat berkurangnya pasokan sedimen dapat diminimalisir [2]. Namun groin yang dibangun pada pantai Salido hanya sebatas pantai Salido saja, sementara pantai Salido merupakan satu 
kesatuan garis pantai dengan pantai Sago seperti dalam Gambar 1.

Penelitian ini bertujuan untuk melihat efektifitas groin yang sudah dibangun dalam menjaga kestabilan garis pantai Salido. Kemudian melihat dampak groin tersebut pada daerah yang tidak terbangun groin seperti pada pantai Sago. Disamping itu penelitian ini diharapkan dapat memberikan manfaat sebagai acuan dalam pengambilan keputusan oleh dinas terkait sebelum pembangunan groin, agar groin yang akan dibangun menjadi tepat sasaran mengingat biaya yang dibutuhkan untuk membangun groin cukup besar.

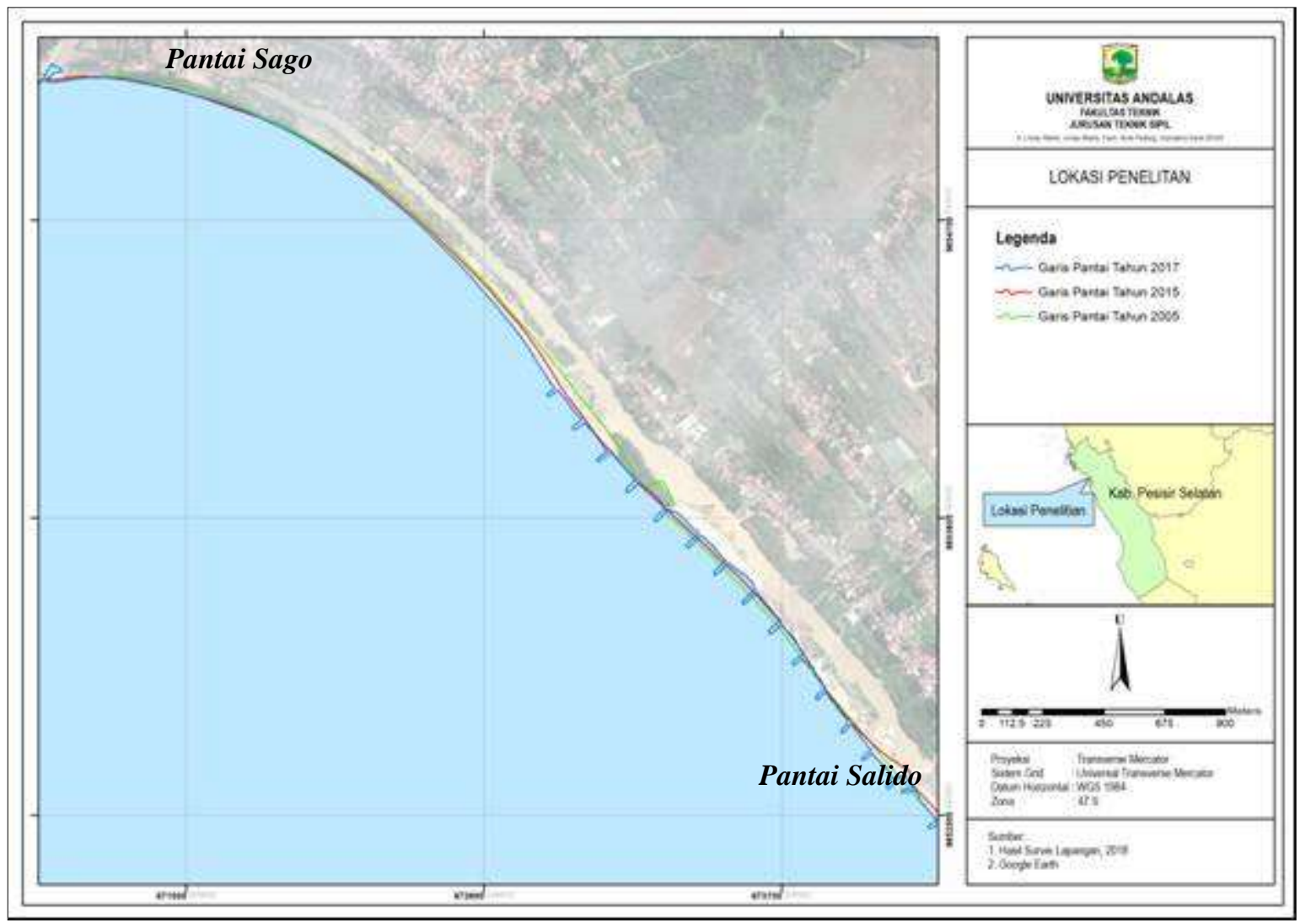

Gambar 1. Lokasi penelitian

\section{TINJAUAN PUSTAKA}

Yustian, dkk [3] melakukan penelitian terhadap efektivitas groin yang dibangun pada pantai Teluk Penyu Kabupaten Cilacap Jawa Tengah. Hasil penelitian menunjukan bahwa groin yang terdapat pada Pantai Teluk Penyu efektif sebagai bangunan stabilitas pantai. Groin tersebut dapat menangkap sedimen yang bergerak sejajar pantai dengan arah gerak dominan dari selatan menuju utara dan dapat meredam energi gelombang yang terjadi. Hasil tumpang tidih (overlay) peta tahun 1983 (sebelum ada groin) dengan peta 2011 menunjukan akresi seluas $168212,21 \mathrm{~m} 2$ atau 16,82 ha yang menyebabkan majunya garis pantai sebesar 60 - 70 meter. Pola perubahan garis Pantai Teluk Penyu selama 5 tahun (tahun 2014-2019) mengalami akresi namun cenderung stabil dengan nilai total akresi dan erosi yang hampir sama yakni sebesar $421 \mathrm{~m} 2$ dan 408,56 m2. Efektivitas groin dianalisa dengan membuat simulasi perubahan garis pantai menggunakan perangkat lunak GENESIS, yang menghasilkan kesimpulan bahwa groin berfungsi secara efektif sebagai bangunan stabilitas pantai.

Thach et all [4] melakukan penelitian di pulau Chat Hai, kota Hai Phong Vietnam. Thach melakukan simulasi menggunakan LITLINE model dengan membagi daerah penelitian menjadi lima segmen berdasarkan karaktersitik erosi dan sadimentasi yang berbeda-beda. Dengan mempertimbangkan kondisi alami dan keadaan social, kemudian dilakukan pemodelan penanganan pantai yang tepat dengan menggunakan LITPACK. Hasil 
pemodelan menunjukkan teknologi penanganan pantai yang cocok untuk menjaga kestabilan garis pantai yang telah terjadi.

Penelitian sekarang berbeda dengan penelitian sebelumnya yang disebutkan di atas.
Disamping melakukan analisa terhadap efektifitas groin yang sudah dibangun penulis juga melakukan analisa perubahan garis pantai pada area yang tidak dibangun groin akibat groin yang sudah dibangun tersebut.

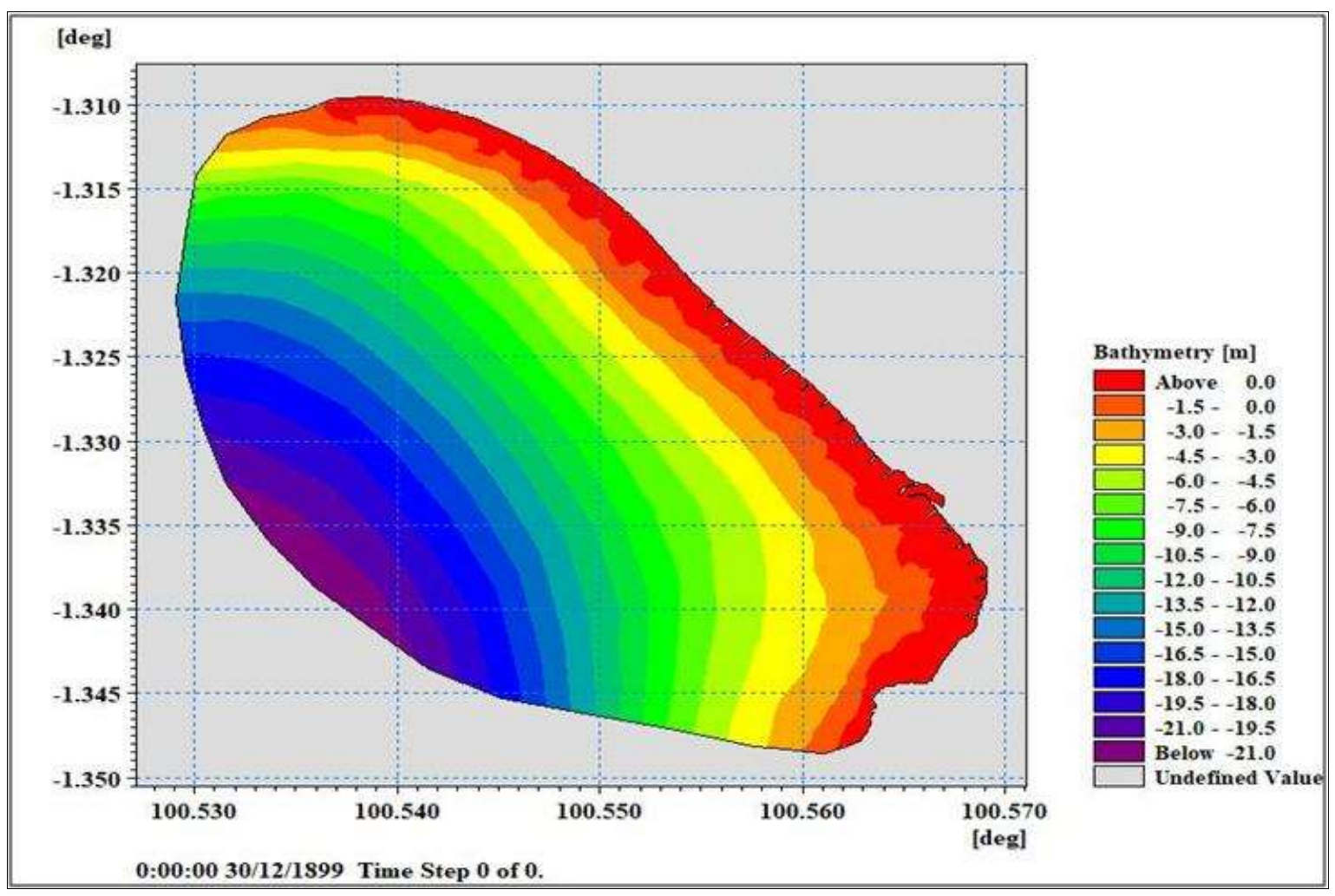

Gambar 2. Batimetri yang digunakan dalam penelitian

\section{METODE PENELITIAN}

\subsection{Digitasi Garis Pantai dan Batimetri}

Data digitasi garis pantai diperoleh dari Google Earth tahun 2005, 2015 (sebelum dibangun groin, dan 2017 (sesudah dibangun groin). Data batimetri diperoleh dari Gebco [5] dengan resolusi 30 arc second atau lebih kurang 1 kilometer, dan diolah menggunakan software Mike 21 dengan hasil seperti Gambar 2.

\subsection{Hindcasting Gelombang}

Mengingat sulitnya memperoleh data gelombang maka dilakukan perhitungan hindcasting gelombang. Hindcasting gelombang adalah peramalan arah dan tinggi gelombang menggunakan data angin lampau. Perhitungan hindcasting gelombang menggunakan data angin 10 tahun (2008-2017) yang diperoleh dari NOAA Earth System Research Laboratory [6]. Perhitungan hindcasting gelombang mengacu pada Shore Protection Manual (SPM 1984) [7].

\subsection{Data Ukuran Butiran Sedimen ( $\left.D_{50}\right)$}

Data ukuran butiran sedimen $\mathrm{D}_{50}$ diperoleh langsung dari pengambilan sampel di loaksi penelitian dan dilakukan analisa di laboratorium. Dari hasil analisa saringan diperoleh nilai $\mathrm{D}_{50}$ sebesar $0,241 \mathrm{~mm}$.

\subsection{Skenario Simulasi Perubahan Garis Pantai dan Validasi Pemodelan}

Simulasi perubahan garis pantai dilakukan dalam beberapa skenario, diantaranya sebelum dibangun groin (tahun 2005-2015), sesudah dibangun groin (tahun 2017), dan simulasi perubahan garis pantai pada daerah yang tidak terbangun groin.

\section{HASIL DAN PEMBAHASAN}

\subsection{Arah Gelombang Dominan}

Dari pengolahan data angin menjadi data gelombang (hindcasting) gelombang diperoleh arah gelombang beserta tingginya dan digambarkan ke dalam diagram mawar 
gelombang dan diagram distribusi frekuensi seperti pada Gambar 3 dan Gambar 4.

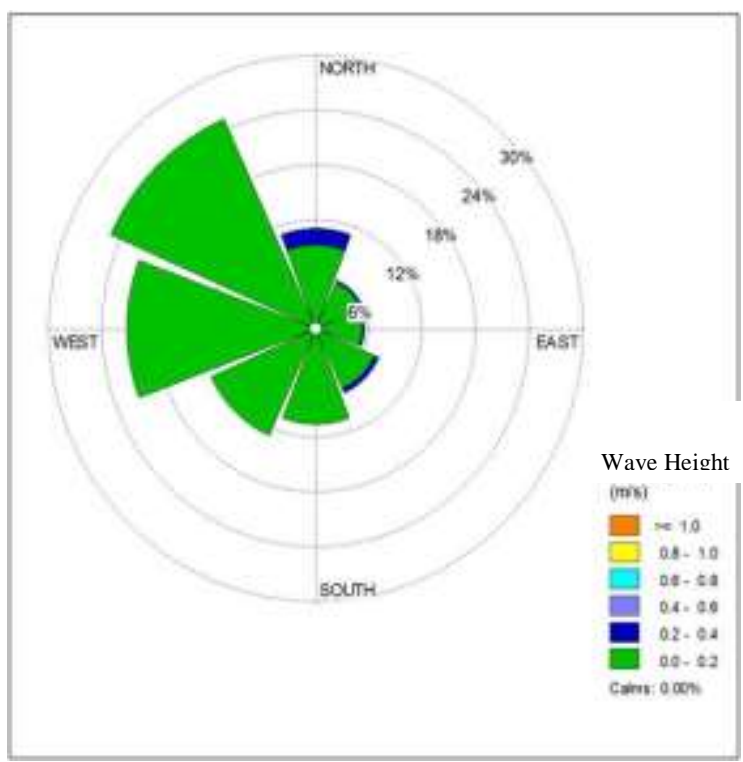

Gambar 3. Wave Rose Pantai Salido

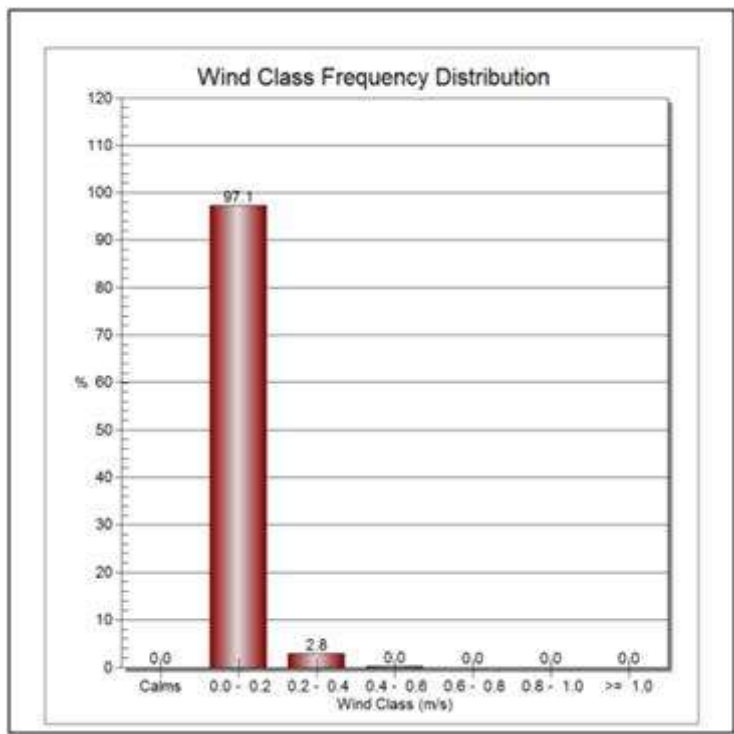

Gambar 4. Diagram distribusi frekuensi gelombang

Dari Gambar 3 terlihat arah gelombang dominan yang terjadi pada pantai Salido selama 10 tahun terakhir (2008-2017). Dari wave rose terlihat gelombang pada pantai Salido didominasi oleh gelombang dengan ketinggian 0-0,2 m dari arah barat laut, barat, barat daya dan selatan. Sedangkan gelombang yang lebih tinggi $(0,2-0,4 \mathrm{~m})$ berasal dari tenggara menuju barat laut.

Dari Gambar 4 terlihat bahwa gelombang didominasi oleh gelombang dengan ketinggian sebesar $0-0,2 \mathrm{~m}$ sebanyak $97,1 \%$ dan gelombang dengan ketinggian 0,2-0,4 m dengan frekuensi sebesar 2,8\% dan 0,4-0,6 sebanyak $0,01 \%$. Dalam proses simulasi GENESIS akan memilah gelombang yang mampu mengangkut matrial sedimen sehingga menyebabkan perubahan garis pantai.

\subsection{Simulasi Perubahan Garis Pantai}

Simulasi dilakukan dengan membagi daerah penelitian menjadi 2 bagian seperti Gambar 5 .Area 1 adalah area yang dibangun groin (Pantai Salido) sedangkan area 2 adalah area yang tidak terbangun groin (Pantai Sago).

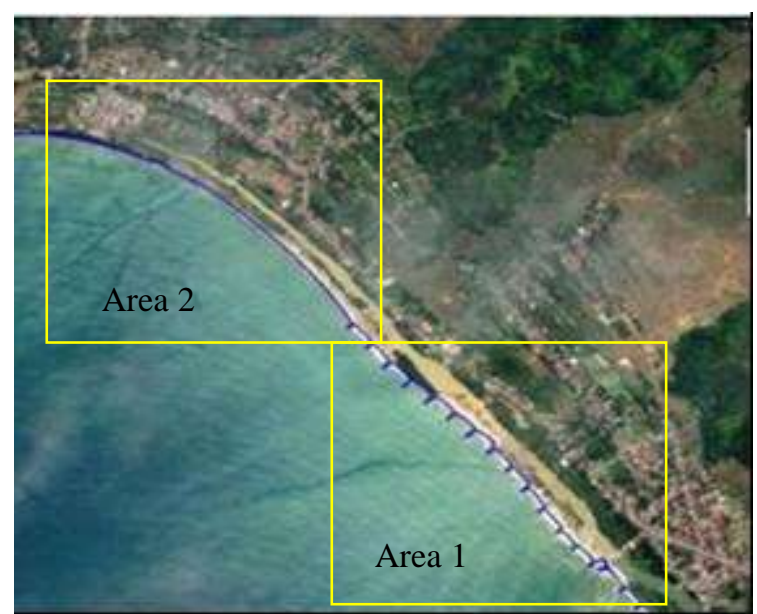

Gambar 5. Pembagian area simulasi

\subsection{Simulasi Perubahan Garis Pantai Area 1}

Simulasi menggunakan garis pantai tahun 2017 setelah dibangunnya groin. Simulasi dilakukan selama 10 tahun ke depan (2017-2027) untuk melihat pola perubahan garis pantai sesudah adanya groin. Dari hasil simulasi terlihat pola akresi dan abrasi yang seimbang dengan adanya groin (Gambar 6). Hal ini menunjukkan bahwa keberadaan groin berfungsi efektif dalam menjaga kestabilan garis pantai dengan kondisi arah dan tinggi gelombang yang ada.

Dari hasil simulasi terjadi total penambahan volume sebesar $1790 \mathrm{~m} 3$. Untuk nilai Q gross (angkutan volume ke kanan) dan $\mathrm{Q}$ nett (angkutan volume ke kanan dikurangi ke kiri) dapat dilihat pada Tabel 1.

Pergerakan transpor volume sangat dominan bergerak ke kanan (barat laut). Hal ini menunjukkan bahwa gelombang yang berpengaruh adalah gelombang dari arah tenggara. 


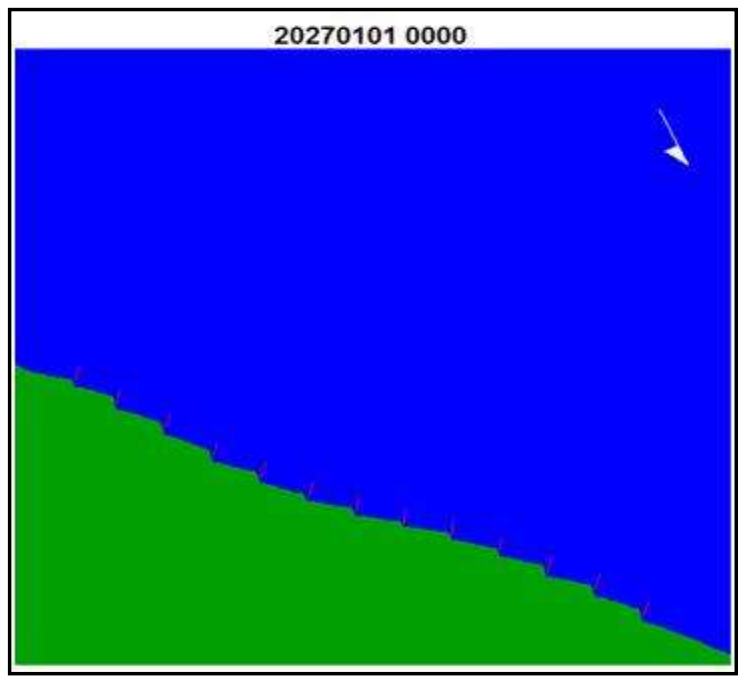

Gambar 6. Simulasi perubahan garis pantai pada area 1 dengan Azimuth $294,66^{\circ}$

Tabel 1. Transpor volume Pantai Salido

\begin{tabular}{c|c|c}
\hline Tahun & Q gross (m3) & Q nett (m3) \\
\hline $2017-2018$ & 931.21 & 900.81 \\
\hline $2018-2019$ & 99.38 & 97.25 \\
\hline $2019-2020$ & 203.81 & 202.74 \\
\hline $2020-2021$ & 651.7 & 650.27 \\
\hline $2021-2022$ & 254.05 & 253.15 \\
\hline $2022-2023$ & 87.3 & 86.46 \\
\hline $2023-2024$ & 77.62 & 76.92 \\
\hline $2024-2025$ & 197.03 & 195.73 \\
\hline $2025-2026$ & 67.42 & 66.92 \\
\hline $2026-2027$ & 91.45 & 90.72 \\
\hline Rata-rata & $\mathbf{2 6 6 . 1}$ & $\mathbf{2 6 2 . 1}$ \\
\hline
\end{tabular}

Hal ini juga disebabkan oleh bentuk batimetri pantai Salido yang berperan dalam membelokkan (refraksi) gelombang pada pantai Salido. Sesuai pernyataan Triatmodjo [8], gelombang yang menuju pantai akan pecah dan membentuk sudut terhadap garis pantai akibat perubahan kedalaman sehingga menyebabkan terjadinya arus sejajar pantai.

Hasil simulasi dengan bangunan pengaman pantai berupa groin menunjukkan bahwa groin yang sudah dibangun efektif dalam menjaga kestabilan garis pantai. Terlihat garis pantai yang terbentuk sudah berupa garis pantai stabil dengan pola erosi dan akresi yang seimbang. Groin juga meningkatkan penambahan volume sedimen sebesar $50 \mathrm{~m} 3$. Sesuai dengan Triatmojo [8] mengatakan bahwa salah satu kelebihan groin diantaranya groin mampu menahan transport sedimen di sepanjang pantai.

\subsection{Dampak Groin Pada Area yang Tidak Terbangun Groin (Area 2)}

Simulasi perubahan garis pantai menggunakan data garis pantai tahun 2017 dan disimulasikan 10 tahun ke depan (sampai 2027). Hasil simulasi dapat dilihat pada Gambar 7.

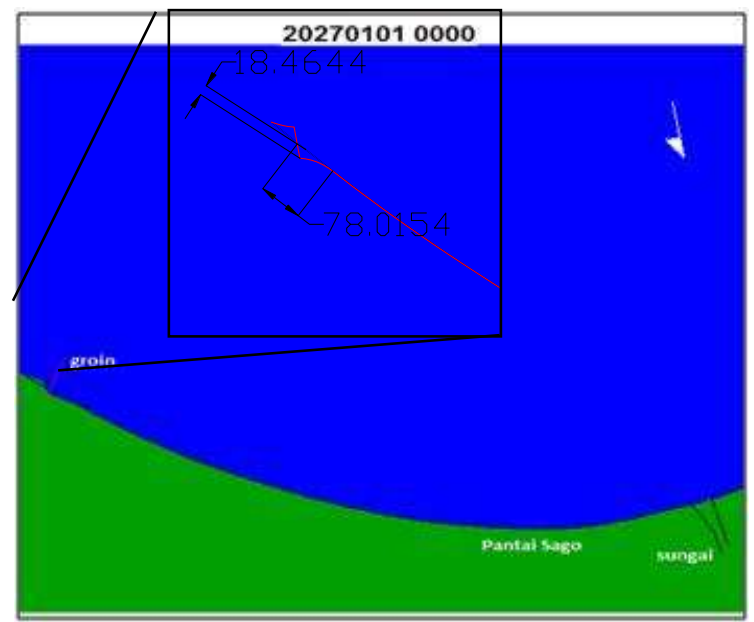

Gambar 7. Hasil simulasi perubahan garis pantai pada area yang tidak dibangun groin

Dari hasil simulasi pada daerah yang tidak terbangun groin menunjukkan pada sisi hilir groin pantai Salido terjadi abrasi sepanjang lebih kurang $78 \mathrm{~m}$ dengan kemunduran garis pantai sejauh lebih kurang 18 m. Namun pada daerah yang tidak terbangun groin (pantai Sago) tidak menunjukkan perubahan yang signifikan. Sedangkan jika dibandingkan dengan tumpang susun citra satelit tahun 2005-2015 (sebelum dibangunnya groin) pantai Sago cenderung mengalami akresi sebesar 0,5 m/tahun dan setelah adanya groin (2015-2017) (Gambar 8) akresi yang terjadi cenderung terhenti. Sedimen yang biasanya terbawa oleh arus yang dominan mengarah ke kanan tertahan oleh groin yang sudah dibangun pada pantai Salido sehingga setelah dibangunnya groin pada pantai Salido lokasi wisata pantai Sago tidak lagi mengalami akresi seperti sebelumnya.

\section{KESIMPULAN DAN SARAN}

\subsection{Kesimpulan}

Dari hasil simulasi terlihat bahwa arah gelombang dominan ke kanan (barat laut) sehingga menyebabkan longshore transport dominan ke kanan (Q nett). 


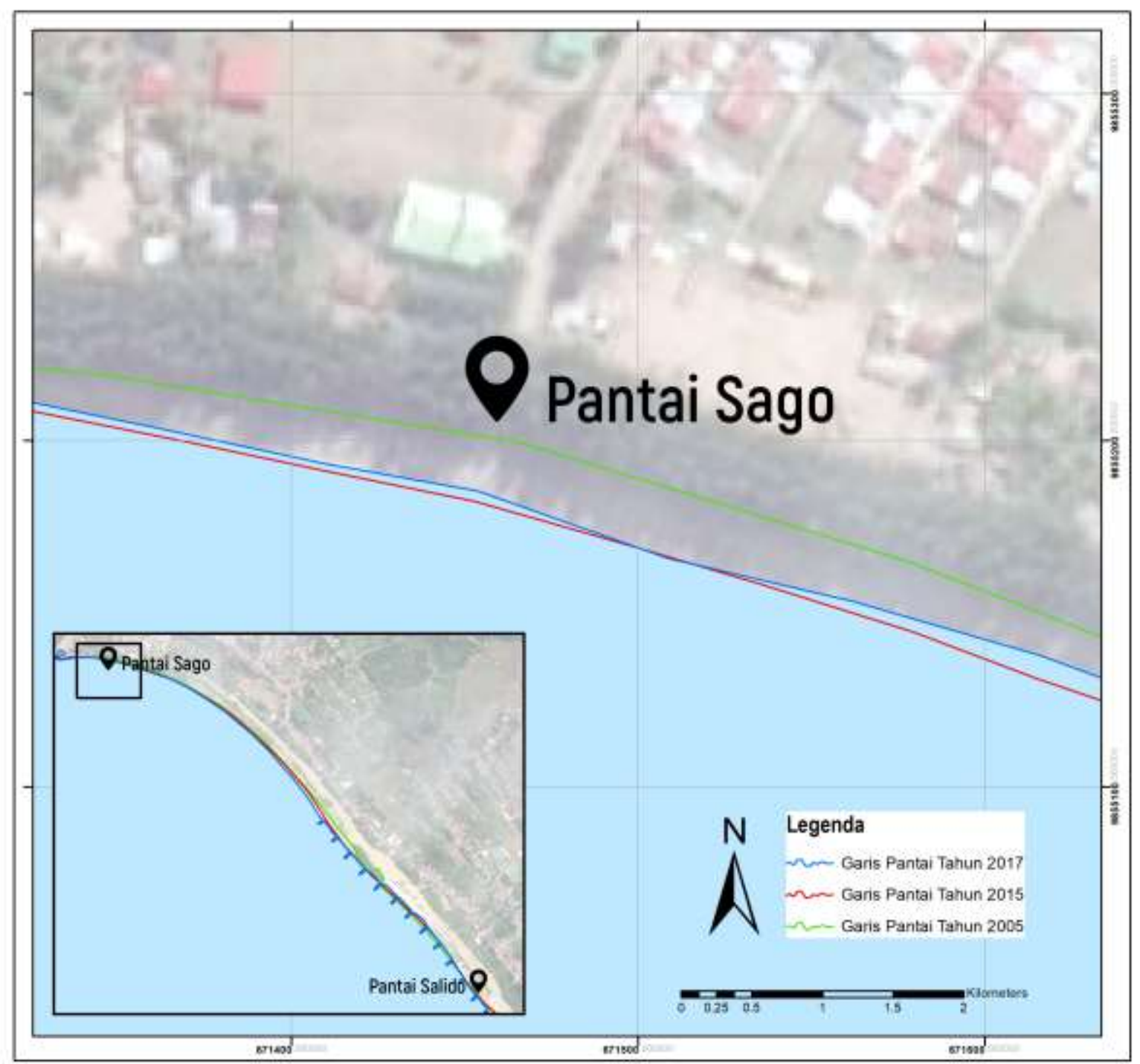

Gambar 8. Tumpang susun garis pantai tahun 2005, 2015 dan 2017 dari citra satelit Google Earth.

Groin yang sudah dibangun pada pantai Salido terlihat efektif dalam menangkap pergerakan sedimen sehingga mampu mempertahankan kestabilan garis pantai Salido terbukti dengan terbentuknya pola akresi dan abrasi yang seimbang pada pantai Salido. Namun hal ini menyebabkan pola akresi yang terbentuk pada pantai Sago selama 10 tahun terakhir (2005-2015) sebelum dibangunnya groin menjadi terhambat. Keberadaan groin pada pantai Salido cenderung menyebabkan abrasi pada sisi hilir groin. Seperti yang terlihat dalam simulasi terjadi abrasi sepanjang $\pm 78 \mathrm{~m}$ dengan kemunduran garis pantai sebesar $\pm 18 \mathrm{~m}$ pada pantai Sago yang tidak terbangun groin, pada posisi yang berbatasan langsung dengan groin tersebut. Abrasi ini dikhawatirkan cenderung bertambah ke sepanjang lokasi wisata pantai Sago.

\subsection{Saran}

Abrasi yang terjadi pada sisi hilir groin terakhir pantai Salido cenderung bertambah, sehingga penulis menyarankan pembangunan groin perlu dilakukan sampai ke sepanjang garis pantai Sago.

Untuk peneliti selanjutnya perlu menggunakan data batimetri hasil pengukuran langsung di lapangan untuk terjaminnya hasil penelitian yang lebih akurat. Selain itu juga perlunya digitasi garis pantai menggunakan peralatan yang lebih akurat seperti citra satelit dengan resolusi yang lebih tinggi ataupun peralatan GPS dengan ketelitian yang sangat tinggi.

\section{DAFTAR PUSTAKA}

[1] Perez-Munoz, et all, Evolution of Longshore Beach Contour Lines Determined by The E.O.F. 
Method, Jurnal Scientia Marina, Vol. 65, 2001: 393-402.

[2] Istijono, B, dkk, Analisis Penilaian Kinerja Bangunan Pengaman Pantai Terhadap Abrasi di Kota Padang, Prosiding Pertemuan Ilmiah Tahunan HATHI XXXI, 2014 : 453-461.

[3] Yustian, dkk, Studi Efektivitas Groin Terhadap Perubahan Garis Pantai diPantai Teluk Penyu Kabupaten Cilacap, Jurnal Oseanografi Vol 5 No 3, 2016.

[4] Thach et all, Studying Shoreline Change Using
LITPACK Mathematical Model (Case Study in Cat Hai Island, Hai Phong City, Vietnam), VNU Journal of Science, Earth Science 23, 2012, 244-252.

[5] https://www. bodc. ac.uk

[6] www.esrl.noaa.gov

[7] CERC, Shore Protection Manual, Vol I-IV, Washington DC, 1984.

[8] Triatmodjo, B, Teknik Pantai, Yogyakarta, 1999. 